\title{
RESEARCH
}

Open Access

\section{Comparing the efficacy and safety of duloxetine and amitriptyline in the treatment of fibromyalgia: overview of systematic reviews}

\author{
Áurea Dias de Farias $^{{ }^{*}}$ (D), Luciana Eberle ${ }^{1}$, Tânia Alves Amador ${ }^{2}$ and Tatiane da Silva Dal Pizzol ${ }^{2}$
}

\begin{abstract}
Background: Duloxetine and amitriptyline are antidepressants used in the treatment of fibromyalgia. In published systematic reviews, there is no agreement about which drug is more effective and safer. This study aimed to compare evidence of the efficacy and safety of duloxetine compared with amitriptyline in the treatment of adult patients with fibromyalgia. This work contributes to guiding clinicians on the use of duloxetine or amitriptyline for the treatment of fibromyalgia and provides information for public health decision-makers.

Methods: Overview of systematic reviews of clinical trials comparing duloxetine and amitriptyline in the treatment of fibromyalgia. The reviews were screened in Cochrane, PubMed, EMBASE, and SRDR with no restrictions on language and year of publication, considering that the research was conducted in July 2018 and updated until May 2020. The selection was based on the following criteria: adult patients with a diagnosis of fibromyalgia treated with duloxetine or amitriptyline, comparing the efficacy and safety in pain, fatigue, sleep, and mood disorder symptoms and quality of life, in addition to the acceptability of these antidepressants. The methodological quality and strength of evidence were assessed using the AMSTAR and GRADE instruments.

Results: Eight systematic reviews were selected. Amitriptyline had low evidence for pain, moderate evidence for sleep and fatigue, and high evidence for quality of life. Duloxetine had high quality of evidence in patients with mood disorders. With low evidence, duloxetine has higher acceptability, but is safer in older patients, while amitriptyline is safer for non-elderly individuals.
\end{abstract}

Conclusion: Both antidepressants are effective in the treatment of fibromyalgia, differing according to the patient's symptoms and profile.

Registration: PROSPERO: CRD42019116101.

Keywords: Fibromyalgia, Duloxetine, Amitriptyline, Systematic review, Overview

\footnotetext{
* Correspondence: aureafarias@gmail.com

${ }^{1}$ Secretaria de Estado da Saúde do Rio Grande do Sul, Porto Alegre, RS, Brasil

Full list of author information is available at the end of the article
}

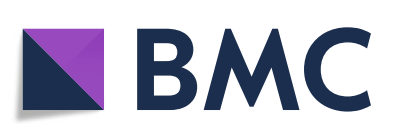

(c) The Author(s). 2020 Open Access This article is licensed under a Creative Commons Attribution 4.0 International License, which permits use, sharing, adaptation, distribution and reproduction in any medium or format, as long as you give appropriate credit to the original author(s) and the source, provide a link to the Creative Commons licence, and indicate if changes were made. The images or other third party material in this article are included in the article's Creative Commons licence, unless indicated otherwise in a credit line to the material. If material is not included in the article's Creative Commons licence and your intended use is not permitted by statutory regulation or exceeds the permitted use, you will need to obtain permission directly from the copyright holder. To view a copy of this licence, visit http://creativecommons.org/licenses/by/4.0/. 


\section{Background}

Fibromyalgia is a syndrome whose etiology is still not fully understood. It is multifactorial and is characterized by chronic, widespread, diffuse musculoskeletal pain, often associated with fatigue, sleep and mood disorders, and a consequent adverse impact on the quality of life. Its diagnosis is very complex, and treatment is multidisciplinary, which can be pharmacological or not [1]. The global prevalence of fibromyalgia is $2.7 \%$, ranging from $0.4 \%$ in Greece to $9.3 \%$ in Tunisia. Mean prevalence is $3.1 \%$ in the Americas, 2.5\% in Europe, and 1.7\% in Asia [2]. In Brazil, a study by Senna et al. [3] recorded a $2.5 \%$ prevalence of the disease, affecting women in more than $90 \%$ of cases.

Pharmacotherapy of fibromyalgia can include diverse therapeutic classes and, among the antidepressants, there are several studies citing duloxetine hydrochloride and amitriptyline. Compared to amitriptyline, launched in 1961, duloxetine is a more recent drug available in the market, released in 2004, and has in its favor a safety profile with fewer anticholinergic effects such as dry mouth, tachycardia, constipation, weight increase, increased intraocular pressure, among others [4].

Systematic reviews are indicating that both duloxetine and amitriptyline are effective in the treatment of fibromyalgia $[5,6]$. However, based on individual analysis of these reviews, one cannot conclude whether these drugs have the same efficacy and safety in the treatment of the symptoms of the illness, such as fatigue, sleep, mood disorder and quality of life.

When selecting pharmacological therapy, it is relevant to consider drug cost analysis as part of the final decision. However, there is a lack of economic studies comparing antidepressants in fibromyalgia [7]. It is known that the one-year treatment with duloxetine in the dosages indicated for fibromyalgia is 2.7 times greater than amitriptyline [8]. In addition, it is important not to neglect patients' social preferences to support the final decision [9].

This study aimed to synthesize evidence on the efficacy, safety, and acceptability of duloxetine in the treatment of adult patients diagnosed fibromyalgia, compared with the effects of amitriptyline, based on systematic reviews of clinical trials.

\section{Methods}

\section{Protocol and registration}

The research protocol was defined and registered in the PROSPERO database (registration number CRD42019116101). The study was reported according to the initial version of the Preferred Reporting Items for OoSRs-PRIO-harms [10].

\section{Study design}

We conducted an overview of systematic reviews. Overview is a method that selects, gathers, and synthesizes results and improves the accessibility of existing evidence. It is used when there are several systematic reviews on similar or related topics [11].

\section{Criteria of eligibility}

The research question was based on the PICO method. We included all systematic reviews of clinical trials that assessed the efficacy and safety of duloxetine and amitriptyline to treat fibromyalgia symptoms (pain, fatigue, sleep and mood disorders, quality of life) and the acceptability of these drugs by adult patients with this disease. Idiom and year of publication were not restricted.

The main outcome of interest was the efficacy of duloxetine and amitriptyline in the treatment of major fibromyalgia-related symptoms. The secondary outcomes were associated with the safety of these drugs, including adverse responses, and adherence to the treatment (acceptability).

\section{Search strategy}

The reviews were identified in the following databases: Cochrane Central Register of Controlled Trials, MEDLINE, EMBASE, and The Systematic Review Data Repository (SRDR). The search was carried out using the following $\mathrm{MeSH}$ (Medical Subject Headings) and DHS (Descriptors in Health Sciences) terms: (fibromyalgia); (duloxetine); (amitriptyline); (systematic review). An additional search strategy was performed in the Epistemonikos platform, specific for systematic reviews, using the terms (title:(abstract:(fibromyalgia AND duloxetine AND amitriptyline AND systematic review)) OR abstract:(abstract:(fibromyalgia AND duloxetine AND amitriptyline AND systematic review))). Database searches were performed in July 2018 and were updated until May 2020.

Gray literature was also searched in the Sociedade Médica de Reumatologia [Medical Society of Rheumatology] and academic dissertations in Google Scholar databases.

\section{Selection of studies and data extraction}

The titles and abstracts were read by two authors (AF and LE), who also read the full text of the studies included. Afterward, old reviews that had been updated were excluded, and the latest one was considered. Other reviews that, when reading, did not meet the eligibility criteria were also disregarded. The data were extracted independently by the reviewers. Any disagreements were resolved by consensus between the two authors or with the senior researchers (TA and TDP).

General information on the reviews, scoring utilized, and the outcomes related to pain, sleep, fatigue, quality of life, acceptability, and safety were collected from the reviews included. 
Data on reviews were extracted and entered into Microsoft Excel ${ }^{\circ}$ datasheets. It was not necessary to contact the selected review's authors to obtain data.

\section{Assessment of the methodological and evidence quality} The methodological quality of the reviews included in the overview was assessed by two independent researchers, as recommended by the Cochrane Handbook for overviews [12], using the Assessment of Multiple Systematic Reviews - AMSTAR instrument [13]. The results of the methodological quality assessed in AMSTAR are rated as "very low quality" ( $\leq 9$ scores), "low quality" (10-11 scores), "moderate quality" (12-13 scores), and "high quality" (14-16 scores). The scores resulting from the assessment of the requirements that were met, as proposed by the instrument.

The quality of evidence of the reviews included was assessed according to the Grading of Recommendations Assessment, Development and Evaluation - GRADE [14]. In the case of overviews, the GRADE is adapted as described in the Cochrane Handbook for Systematic Reviews of Interventions [12]. We did not re-evaluate each individual study of the selected reviews. The overview reviewers assessed and documented the criteria presented in the reviews included, and descriptively reported the quality of the reviews' datasets, using the analysis made by the reviews' authors. The criteria used to determine the reduced quality of the evidence were: risk of bias in the studies included, inconsistency, indirect evidence, imprecision, and publication bias. Due to subjectivity in the application of the criteria, a calculation was developed to allow a reproducible attribution of the GRADE' s evidence levels. For each outcome, the above five criteria in the reviews selected were assessed. The reviewers worked to ensure consensus and consistency of entering objective data related to these criteria into a worksheet, and according to the number of evidence downgrades in the number of reviews that addressed the outcome, the following rating was used: $0-1.00$ : not serious; $1.01-1.50$ : serious; $1.51-2.00$ : very serious. This classification was applied to the narrative table available in the Software GRADE Pro GDT [15] and was adapted to allow an interpretation of the results, determining the grading of the evidence found as high, moderate, low, or very low.

\section{Calculation of overlapping}

One of the major challenges of an overview is the overlap of studies, that is, when there are individual studies present in more than one review. We calculated the corrected covered area - CCA, a method that divides the total number of individual studies by the product between the number of reviews and the number of nonrepeated studies [16].

\section{Results}

A total of 123 abstracts were found, and after exclusion of those that did not meet the criteria of eligibility, 14 articles remained. One of them [17] was out because it is not published yet. A total of 13 articles were read in full. Out of these, five articles were excluded, remaining eight analyzed reviews [5, 6, 18-23].

Figure 1 is a flowchart of the searches and exclusions. Table 1 describes the main characteristics of the studies included, and Table 2 shows the reviews excluded and justifications.

The methodological qualities of the included reviews varied largely, as shown in Table 3 . Table 4 presents the assessment of the quality of evidence, according to GRADE.

Regarding overlapping, the calculation of the area covered and corrected for this overview indicated $40 \%$ of overlap in individual studies. The result indicates that there may be duplicates in the systematic reviews, which may have an impact on data extraction, because the results of the overlapped studies may influence the overall analyses of results. For this reason, a systematic review must be conducted when there are no reviews with the same objective or when the existing ones are outdated [16].

\section{Discussion and conclusions}

This overview summarized the results of eight systematic reviews on efficacy, safety and acceptability of duloxetine in the treatment of adult patients diagnosed with fibromyalgia, compared with amitriptyline. Differences in efficacy varied depending on the symptom.

Regarding pain, amitriptyline was more effective in three (37.5\%) of the selected reviews [5, 19, 21]. However, the evidence was considered of low quality in the GRADE analysis, and it should be emphasized that four reviews $[6,20,22,23]$ did not find a significant difference between the two drugs used in the management of this symptom. Both drugs are recommended by the European League Against Rheumatism [24], Sociedade Brasileira de Reumatologia [1] [Brazilian Society of Rheumatology], and the Canadian Guidelines for the Diagnosis and Management of Fibromyalgia Syndrome [25]. The findings are consistent with a study [26], which point out that antidepressants, in general, have not yet shown quality evidence that they have a significant effect on pain in fibromyalgia. It would seem that the results are related to the difficulty of measuring the real drug-induced potentiation of descending pathways that inhibit pain in the central nervous system [27].

Regarding the sleep disorders outcome, amitriptyline was more effective in five $(62.5 \%)$ of the selected 


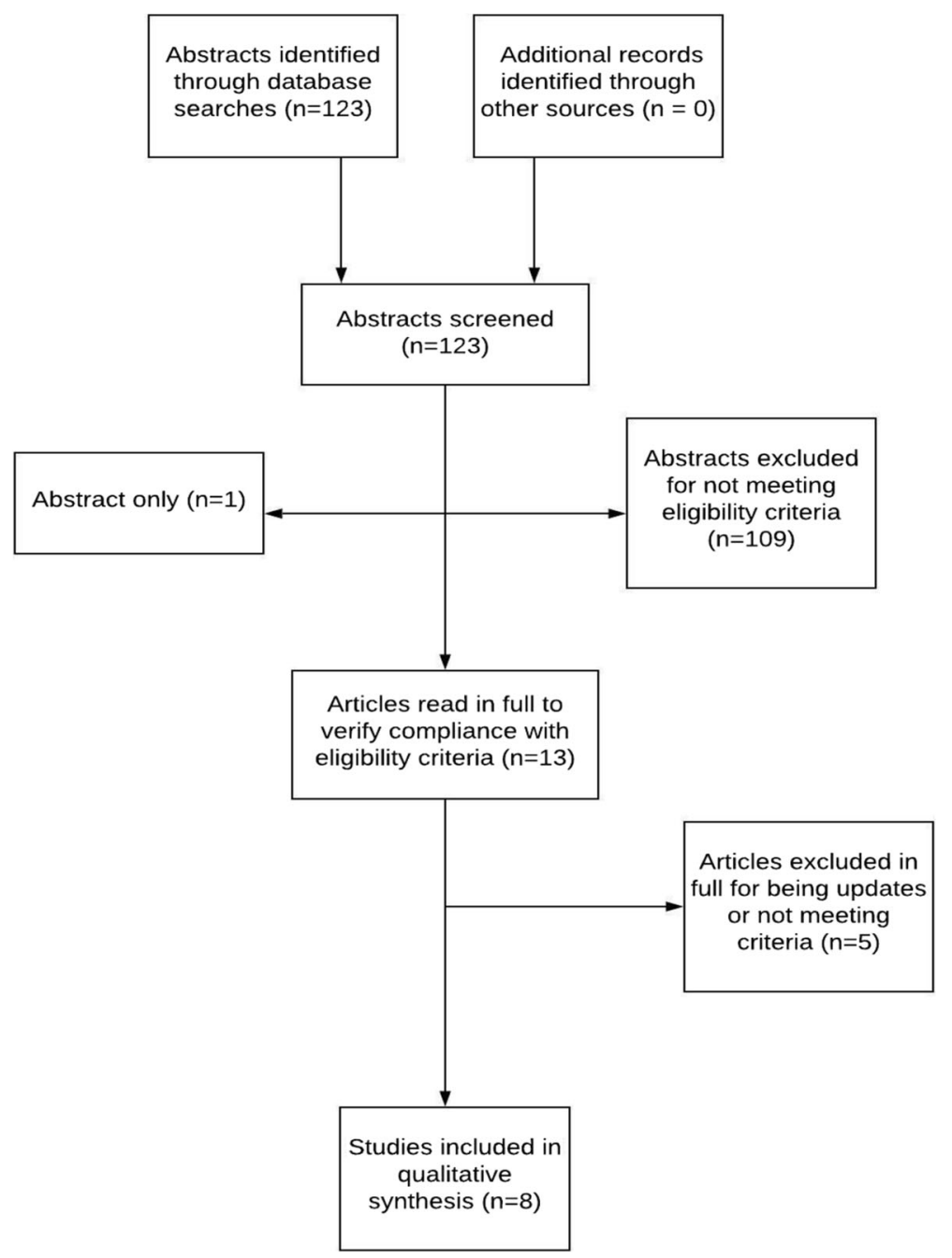

Fig. 1 Study flow diagram

reviews [5, 18, 19, 21, 23] with moderate quality of evidence. Duloxetine did not exhibit proven efficacy in sleep in any of the reviews. This corroborates the findings of specific research on sleep disorders in fibromyalgia [28], which concluded that amitriptyline is more efficacious than duloxetine for this specific symptom probably due to its actions on cortical areas from the central nervous system that regulate sleep.

Regarding fatigue, six (75\%) reviews [5, 18, 19, 21-23] favored amitriptyline. Duloxetine did not have proven efficacy for fatigue in any of the reviews examined. The quality of evidence was considered moderate. However, fatigue has an extremely complex pathophysiology that requires a comprehensive approach that goes beyond the use of antidepressants and it is not possible to explain the results found definitively.
Regarding mood disorders, $50 \%$ of the reviews selected [5, 18, 19, 22] addressed this outcome, and all of them showed that duloxetine is more efficacious than amitriptyline in the management of depressionrelated symptoms and mood disorders with high quality of evidence. Therefore, duloxetine would be the first option when this is the main symptom of patients with fibromyalgia. A systematic review carried out in 2016 [29] indicated an average prevalence of $52 \%$ of depression in patients with fibromyalgia; therefore, it is necessary to consider the potentiality of indication for treatment with duloxetine if a mood disorder is, in fact, the major symptom. The results are in agreement with the findings of a study conducted in 2005 [30], which indicated that fibromyalgia-associated depression will often require non-selective reuptake inhibitors, such as duloxetine. 
Table 1 Characteristics of the systematic reviews included

\begin{tabular}{|c|c|c|c|c|c|c|}
\hline $\begin{array}{l}\text { Author, } \\
\text { year }\end{array}$ & $\begin{array}{l}\text { Number } \\
\text { of } \\
\text { Studies } \\
\text { DLX }\end{array}$ & $\begin{array}{l}\text { Number } \\
\text { of } \\
\text { Studies } \\
\text { AMT }\end{array}$ & $\begin{array}{l}\text { Participants } \\
\text { Included }\end{array}$ & Objectives & Criteria for Inclusion & Criteria for Exclusion \\
\hline
\end{tabular}

\begin{tabular}{|c|c|c|c|c|c|}
\hline $\begin{array}{l}\text { Thorpe } \\
\text { et al., } \\
2018 \\
{[18]}\end{array}$ & 2 & 1 & 133 & $\begin{array}{l}\text { To assess the efficacy, safety } \\
\text { and tolerability of } \\
\text { combination of drugs with } \\
\text { monotherapy or placebo, or } \\
\text { both, in the treatment of } \\
\text { FMS }\end{array}$ & $\begin{array}{l}\text { Double-blind RCT } \\
\text { comparing combinations of } \\
\text { two or more drugs with } \\
\text { placebo or other } \\
\text { comparatives, or both, in } \\
\text { the treatment of FMS }\end{array}$ \\
\hline
\end{tabular}

$\begin{array}{lllll}\begin{array}{l}\text { Sommer } 10 \\ \text { et al., } \\ 2017\end{array} & 14 & 6038 & \begin{array}{l}\text { To assess the efficacy and } \\ \text { safety of drugs and non- } \\ \text { drug therapy in the treat- } \\ \text { ment of FMS }\end{array} \\ \begin{array}{l}\text { Smith } \\ \text { et al., } \\ 2011\end{array} & 24 & 1368 & \begin{array}{l}\text { To compare the efficacy } \\ \text { and harms of drugs used in } \\ \text { the treatment of FMS }\end{array}\end{array}$

Randomized clinical trials with drugs used to treat FMS, in databases, nonpublished articles and specialists' opinion

Studies with patients with the treatment of FMS

[20]

Häuser $\quad 4 \quad 10 \quad 2023$

et al.,

et al.,

2008

[22]

$\begin{array}{llll}\text { Roskell } & 2 & 5 & 538\end{array}$

et al.,

2011 [6]
To assess and compare the efficacy and acceptability of amitriptyline (AMT), duloxetine (DLX) and milnacipran (MLN) antidepressants in the treatment of FMS

To review systematically the efficacy of antidepressants in the treatment of FMS FMS, according to the ACR criteria of 1990 and 2010 , drugs and direct and indirect comparisons, assessing efficacy and damages

RCT comparing AMT, DLX or MLN with placebo, assessing at least one FMS key domain: pain, sleep, fatigue or health-related continuation rate

FMS or CWP diagnosis based on recognized criteria, controlled study design with a control group who received any other well-defined treatment; treatment with antidepressants, and measurement of specific symptom results

Randomized Controlled Clinical Trials with at least 4-week duration with pa-
To compare pain response to licensed drugs or drugs commonly used in fibromyalgia, also addressing treatment discontinuation due to adverse reactions
To determine the efficacy of antidepressants in the treatment of FMS through meta-analysis and randomized controlled clinical trials
Single-blind studies,

VAS, NPS, complementary studies to pain those already selected, non- reduction of randomized, studies with other therapies and with patients having diverse fibromyalgia diseases

Studies with downgraded quality evidence according to the application of the GRADE method used by the authors

Studies with ineligible results, intervention, $30 \%$ or more and $50 \%$ or more, FIQ, NNTH

$50 \%$ pain reduction, NNTB, VAS, $\mathrm{FIQ}$ involving the use of diverse quality of life; treatment displacebo, usual treatment or tients aged 18 years or over with clinical FMS diagnosis, using Duloxetine $(60 \mathrm{mg} /$ day), Fluoxetine (40 to 50 mg / day), Gabapentin (2400 mg / day), Milnacipran (100 or 200 mg / day), Placebo, Pramipexol $4.5 \mathrm{mg}$ / day), Pregabalin (300 or $450 \mathrm{mg} /$ day), TCA (amitriptyline 25 to $75 \mathrm{mg} /$ day or cyclobenzaprine $1030 \mathrm{mg} /$ day), Tramadol with paracetamol (200 to $300 \mathrm{mg} /$ day)

Patients effectively diagnosed FMS, RCT with one control group receiving placebo and one group treated with antidepressants (TCA, SSRIs, population, publication and $\mathrm{MFI}, \mathrm{MAF}$, VAS, FIQ
RCTs with combination of drugs with any other treatment

Treatment of no interest for $\mathrm{FIQ}, \mathrm{BDI}$ meta-analysis, no major outcome reported, different treatment doses, study not properly controlled, duplicated or of short duration, poor quality testing and when the article was irretrievable

Studies assessing cyclobenzaprine, Sadenosylmethionine, or antidepressant combinations. Studies where only categorial data were
VAS, 30\%

pain reduction, NPS, NNTB, Cohen's category, VAS, FIQ

VAS, tender point count, VAS, BDI, HAM-D, FIQ

.

$\begin{array}{ll}\begin{array}{l}\text { Häuser } 3 \quad 7 \quad 927 \\ \text { et al., } \\ 2009[5]\end{array} & \begin{array}{l}\text { To determine the efficacy } \\ \text { of antidepressants in the } \\ \text { treatment of FMS through } \\ \text { meta-analysis and random- } \\ \text { ized controlled clinical trials }\end{array}\end{array}$


Table 1 Characteristics of the systematic reviews included (Continued)

\begin{tabular}{|c|c|c|c|c|c|c|c|}
\hline $\begin{array}{l}\text { Author, } \\
\text { year }\end{array}$ & $\begin{array}{l}\text { Number } \\
\text { of } \\
\text { Studies } \\
\text { DLX }\end{array}$ & $\begin{array}{l}\text { Number } \\
\text { of } \\
\text { Studies } \\
\text { AMT }\end{array}$ & $\begin{array}{l}\text { Participants } \\
\text { Included }\end{array}$ & Objectives & Criteria for Inclusion & Criteria for Exclusion & Scales \\
\hline & & & & & SNRIs or MAOIs) & $\begin{array}{l}\text { provided and studies with } \\
\text { incomplete data }\end{array}$ & \\
\hline $\begin{array}{l}\text { Perrot } \\
\text { et al., } \\
2008 \\
{[23]}\end{array}$ & 2 & 4 & 910 & $\begin{array}{l}\text { To review evidences of use } \\
\text { of antidepressants in painful } \\
\text { rheumatological conditions }\end{array}$ & $\begin{array}{l}\text { Articles published between } \\
1966 \text { and } 2007 \text { in } 5 \\
\text { European idioms, } \\
\text { addressing the use of } \\
\text { antidepressants in various } \\
\text { rheumatological conditions, } \\
\text { including FMS. The authors } \\
\text { attributed a rating scale } \\
\text { based on the Jadad } \\
\text { method (0-5), including } \\
\text { studies with scoring above } \\
2\end{array}$ & $\begin{array}{l}\text { Articles that were scored } \\
\text { below } 2 \text { in the Jadad scale }\end{array}$ & $\begin{array}{l}\text { VAS, FIQ, } \\
\text { NRS }\end{array}$ \\
\hline
\end{tabular}

a FMS Fibromyalgia, DLX Duloxetine, AMT Amitriptyline, RCT Randomized Clinical Trial, ACR American College of Rheumatology, CWP Chronic Widespread Pain, TCA Tricyclic Antidepressant, SSRIs Selective Serotonin Reuptake Inhibitor, SNRIs Serotonin and Noradrenaline Reuptake Inhibitor, MAOIs Monoamine Oxidase Inhibitors, VAS Visual Analog Scale, NPS Numeric Pain Scale, FIQ Fibromyalgia Impact Questionnaire, NNTB Number needed to treat for an additional benefit, NNTH Number needed to treat to prevent one additional harm, MAF Multidimensional Assessment of Fatigue, MFI Multidimensional Fatigue Inventory, BDI Beck Depression Inventory, HAM-D Hamilton Depression Scale, BDI Brief Pain Inventory, NRS Numeric Rating Scale, HRQL Health-related Quality of Life

These drugs have fewer adverse reactions than the tricyclic antidepressants and are much more effective in the control of depression.

Regarding the quality of life, in two out of five reviews that addressed this outcome, amitriptyline had a better result $[19,21]$. The evidence was considered of high quality. However, for the specialists who developed the Consenso Brasileiro de Fibromialgia [1] [Brazilian Consensus on Fibromyalgia], both medicines are recommended with the same level of evidence for the management of quality of life. It would seem that divergence in results occur due to the subjectivity of perception of the quality of life, which, for many patients, can be directly associated with their level of pain or in the way pain interferes with the emotional aspect [31].

Regarding acceptability and safety, the studies pointed out that was treatments with duloxetine had less discontinuation of therapy due to adverse reactions, but amitriptyline was slightly favored regarding safety. However, the evidence was considered of low quality and highlighted that the reviews with the best quality that addressed safety and acceptability $[20,21]$ did not find significant differences between both medicines. Both drugs have diverse adverse reactions, and these outcomes must be considered with caution, case by case when making a clinical decision.

It should be noted that according to the American Geriatrics Society [32], there is a strong recommendation with high quality of evidence against amitriptyline in older adults, which should be avoided because of its anticholinergic effect, causing sedation and orthostatic hypotension. Thus, for older patients, duloxetine would be the safer choice.

This overview has some limitations. The majority of the studies were conducted before 2010, before changes in the fibromyalgia diagnosis criteria, which

Table 2 Studies excluded for not having met the eligibility criteria

\begin{tabular}{ll}
\hline Study excluded & $\begin{array}{c}\text { Exclusion } \\
\text { code }\end{array}$ \\
\hline HÄUSER W, WOLFE F, TÖLLE T, ÜÇEYLER N, SOMMER C. The Role of Antidepressants in the Management of Fibromyalgia Syndrome: A & 4 \\
Systematic Review and Meta-Analysis. CNS Drugs. 2012 Apr; 26 (4):297-307. & \\
CHOY E, MARSHALL D, GABRIEL ZL, MITCHELL SA, GYLEE E, DAKIN HA. A Systematic Review and Mixed Treatment Comparison of the & 4 \\
Efficacy of Pharmacological Treatments for Fibromyalgia. Seminars in Arthritis and Rheumatism. 2011 Dec; 41 (3):335-345.e6. \\
SULTAN A, GASKELL H, DERRY S, MOORE RA. Duloxetine for painful diabetic neuropathy and fibromyalgia pain: systematic review of \\
randomised trials. BMC Neurol. 2008 Dec; 8 (1):29.
\end{tabular}

a) Complete articles considered for inclusion, but excluded for not having met the criteria. Exclusion codes: $1=$ ineligible outcome, $2=$ ineligible intervention, $3=$ ineligible population, $4=$ ineligible methodology.

b) The other two papers were old versions of the study of Sommer et al., (2017). 
Table 3 Methodological quality of the systematic reviews included in the overview

\begin{tabular}{ll}
\hline Author, year & $\begin{array}{l}\text { Methodological quality } \\
\text { (AMSTAR) }\end{array}$ \\
\hline Thorpe et al., 2018 [18] & $12 / 16$ - moderate \\
Sommer et al.,2017 [19] & $10 / 16$ - low \\
Smith et al., 2011 [20] & $15 / 16$ - high \\
Roskell et al., 2011 [6] & $13 / 16$ - moderate \\
Häuser et al., 2011 [21] & $14 / 16$ - high \\
Häuser et al., 2009 [5] & $14 / 16$ - high \\
Üçeyler et al., 2008 [22] & $9 / 16$ - very low \\
Perrot et al., 2008 [23] & $7 / 16$ - very low \\
\hline
\end{tabular}

basically considered palpation of tender points. Some patients probably were excluded, considering the new form of diagnosis, which considers the pain intensity associated with the degree of severity of other symptoms [33], which could lead to a selection bias.

There are challenges in common with the routine of systematic reviews and overviews, such as the management of large volumes of information and extracted datasets as well as the time available, resources, and the ability to make consensual decisions between the authors and reviewers. In the overview case, we still have the aggravating issue of studies overlapping, inherent to the level of analysis, which encompasses systematic reviews and not individual studies [34].

It was observed that, in some reviews, studies with amitriptyline are of lower methodological quality compared with those with duloxetine. This finding can be explained by the fact that they are older studies, considering that clinical trials have improved over time, making use of the policy of application of trial registration and study assessment tools [35].

In conclusion, both drugs can be used in the treatment of fibromyalgia, depending on the set of predominant key symptoms. The results of analyses indicate recommendation in favor of amitriptyline with low evidence for pain, moderate evidence for sleep and fatigue, and high evidence for the quality of life. Duloxetine is recommended with high quality of evidence when the patients have mood disorder as a major symptom, has more acceptability, and is the first choice for older patients for safety reasons. The

Table 4 Quality of evidence of the reviews included according to GRADE

\begin{tabular}{|c|c|c|c|c|c|c|c|c|c|}
\hline $\begin{array}{l}\text { No. } \\
\text { studies }\end{array}$ & $\begin{array}{l}\text { Study } \\
\text { design }\end{array}$ & $\begin{array}{l}\text { Risk of } \\
\text { Bias }\end{array}$ & Inconsistency & $\begin{array}{l}\text { Indirect } \\
\text { evidence }\end{array}$ & Imprecision & $\begin{array}{l}\text { Other } \\
\text { considerations }\end{array}$ & Impact & Confidence & Importance \\
\hline \multicolumn{10}{|l|}{ Pain } \\
\hline 8 & $\begin{array}{l}\text { SR of } \\
\text { CT }\end{array}$ & $\begin{array}{l}\text { Not } \\
\text { serious }\end{array}$ & Serious ${ }^{a}$ & $\begin{array}{l}\text { Not } \\
\text { serious }\end{array}$ & Not serious & $\begin{array}{l}\text { Highly } \\
\text { suspicious }\end{array}$ & Favors AMT & $\begin{array}{l}++ \\
\text { Low }\end{array}$ & Critical \\
\hline \multicolumn{10}{|l|}{ Sleep } \\
\hline 6 & $\begin{array}{l}\text { SR of } \\
C T\end{array}$ & $\begin{array}{l}\text { Not } \\
\text { serious }\end{array}$ & Serious $^{a}$ & $\begin{array}{l}\text { Not } \\
\text { serious }\end{array}$ & Not serious & None & Favors AMT & $\begin{array}{l}+++ \\
\text { Moderate }\end{array}$ & Critical \\
\hline \multicolumn{10}{|l|}{ Fatigue } \\
\hline 7 & $\begin{array}{l}\text { SR of } \\
C T\end{array}$ & $\begin{array}{l}\text { Not } \\
\text { serious }\end{array}$ & Not serious & $\begin{array}{l}\text { Not } \\
\text { serious }\end{array}$ & Not serious & $\begin{array}{l}\text { Highly- } \\
\text { suspicious } \\
\text { publication } \\
\text { bias }\end{array}$ & Favors AMT & $\begin{array}{l}+++ \\
\text { Moderate }\end{array}$ & Critical \\
\hline \multicolumn{10}{|c|}{ Mood Disorder } \\
\hline 4 & $\begin{array}{l}\text { SR of } \\
\text { CT }\end{array}$ & $\begin{array}{l}\text { Not } \\
\text { serious }\end{array}$ & Not serious & $\begin{array}{l}\text { Not } \\
\text { serious }\end{array}$ & Not serious & None & Favors DLX & $\begin{array}{l}\stackrel{++++}{\text { High }} \\
\text { - }\end{array}$ & Critical \\
\hline \multicolumn{10}{|c|}{ Quality of life } \\
\hline 5 & $\begin{array}{l}\text { SR of } \\
\text { CT }\end{array}$ & $\begin{array}{l}\text { Not } \\
\text { serious }\end{array}$ & Not serious & $\begin{array}{l}\text { Not } \\
\text { serious }\end{array}$ & Not serious & None & Favors AMT & $\begin{array}{l}++++ \\
\text { High }\end{array}$ & Critical \\
\hline \multicolumn{10}{|c|}{ Safety and acceptability } \\
\hline 7 & $\begin{array}{l}\text { SR of } \\
C T\end{array}$ & $\begin{array}{l}\text { Not } \\
\text { serious }\end{array}$ & Serious $^{b}$ & $\begin{array}{l}\text { Not } \\
\text { serious }\end{array}$ & Not serious & $\begin{array}{l}\text { Highly } \\
\text { suspicious } \\
\text { publication } \\
\text { bias }\end{array}$ & $\begin{array}{l}\text { DLX with higher acceptability and safety } \\
\text { for elderlies; AMT with higher safety for } \\
\text { non-elderlies }\end{array}$ & $\begin{array}{l}++ \\
\text { Low }\end{array}$ & Critical \\
\hline
\end{tabular}


results are aligned with the already-recognized complexity of this disease. This overview contributes to guiding clinicians and decision-makers in public health policies based on systematic reviews that addressed the use of antidepressants in the management of fibromyalgia.

\section{Acknowledgements}

Not applicable.

\section{Authors' contributions}

AF conceived the study, performed data collection, analysis, review and interpretation, and drafted the manuscript. LE conducted data collection, analysis, review and interpretation and contributed to the writing of the manuscript. TA conceived the study, conducted data analysis and interpretation and contributed to the writing of the manuscript. TDP contributed to the study conception and the writing of the manuscript. The authors read and approved the final manuscript.

\section{Funding}

FAPERGS: Research Project for SUS -PPSUS - Notice FAPERGS/MS/CNPq/ SESRS n. 03/2017.

\section{Availability of data and materials}

The datasets used and/or analyzed during the current study are available from the corresponding author on reasonable request.

\section{Ethics approval and consent to participate}

Not applicable.

\section{Consent for publication}

Not applicable.

\section{Competing interests}

The authors declare that they have no competing interests.

\section{Author details}

${ }^{1}$ Secretaria de Estado da Saúde do Rio Grande do Sul, Porto Alegre, RS, Brasil. ${ }^{2}$ Universidade Federal do Rio Grande do Sul - Faculdade de Farmácia Programa de Pós-Graduação em Assistência Farmacêutica, Porto Alegre, RS, Brasil.

Received: 23 April 2020 Accepted: 23 June 2020

Published online: 08 July 2020

\section{References}

1. HEYMANN RE, PAIVA E, HELFENSTEIN M, POLLAK D, MARTINEZ J, PROVENZA $J R$, et al. Brazilian consensus on the treatment of fibromyalgia. Brazilian J Rheumatol. 2010;50(1):56-66Available from. https://doi.org/10.1590/S048250042010000100006

2. QUEIROZ LP. Worldwide epidemiology of fibromyalgia. Curr Pain Headache Rep. 2013;17(8):356. Available from https://doi.org/10.1007/s11916-013-03565. Accessed 18 Mar 2019

3. SENNA ER, PEREIRA VB, CICONELLI RM, FERRAZ MB. Prevalence of rheumatic diseases in Brazil: A study using the COPCORD approach. J Rheumatol. 2020: 5 Available from: http://www.jheum.org/content/31/3/594.

4. CHAKR R, Xavier R. Fibromyalgia: practical principles that assist in the indication and adjustment of drug treatment. J Bras Med. 2014;102(6) [cited 2019 Mar 31]. Available from: https://pesquisa.bvsalud.org/portal/resource/ pt/lil-737128.

5. HÄUSER W, BERNARDY K, ÜÇEYLER N, Sommer C. Treatment of fibromyalgia syndrome with antidepressants: A meta-analysis. JAMA. 2009;301(2): 198Available from. https://doi.org/10.1001/jama.2008.944.

6. ROSKELL NS, BEARD S, ZHAO Y, KIM LE TK. A meta-analysis of pain response in the treatment of fibromyalgia. Meta-analysis of fibromyalgia treatments. Pain Pract. 2011;11(6):516-27. https://doi.org/10.1111/j.1533-2500.2010. 00441.x

7. ROBINSON RL, JONES ML. In search of pharmacoeconomic evaluations for fibromyalgia treatments: a review. Expert Opin Pharmacother. 2006;7(8): 1027-39Available from:. https://doi.org/10.1517/14656566.7.8.1027.
8. HORSLEY W. Cost comparison charts. RDTC. 2020;78. Available from: http:// gmmmg.nhs.uk/docs/cost_comparison_charts.pdf. [cited 2020 Jun 05].

9. RICHARDSON J, Schlander M. Health technology assessment (HTA) and economic evaluation: efficiency or fairness first. Journal of Market Access \& Health Policy. 2019;7(1):1557981. https://doi.org/10.1080/20016689.2018. 1557981.

10. BOUGIOUKAS KI, LIAKOS A, TSAPAS A, NTZANI E, Haidich A. Preferred reporting items for overviews of systematic reviews including harms checklist: a pilot tool to be used for balanced reporting of benefits and harms. J Clin Epidemiol. 2018;93:9-24. https://doi.org/10.1016/j.jclinepi.2017.10.002.

11. HUNT H, POLLOCK A, CAMPBELL P, ESTCOURT L, BRUNTON G. An introduction to overviews of reviews: planning a relevant research question and objective for an overview. Syst Rev. 2018;7(1):39. https://doi.org/10. 1186/s13643-018-0695-8

12. BECKER LA, Oxman AD. Chapter 22: overviews of reviews. In: Higgins JPT, Green S, editors. Cochrane handbook for systematic reviews of interventions. Version 5.1.0 [updated march 2011]. The Cochrane collaboration; 2011Available from: www.cochrane-handbook.org. https://doi. org/10.1002/9780470712184.ch22.

13. SHEA BJ, REEVES BC, WELLS G, THUKU M, HAMEL C, MORAN J, et al. AMSTAR 2: a critical appraisal tool for systematic reviews that include randomized or non-randomized studies of healthcare interventions, or both. BMJ. 2017;j4008. https://doi.org/10.1136/bmj.j4008.

14. SCHÜNEMANN H, BROZEK J, GUYATT G, OXMAN A. GRADE handbook for grading quality of evidence and strength of recommendations. Updated October 2013. The GRADE working group; 2013. Available from: guidelinedevelopment.org/handbook.

15. GRADEpro GDT. GRADEpro guideline development tool [software]; 2015 McMaster University, (developed by Evidence Prime, Inc.). Available from: gradepro.org

16. PIEPER D, Antoine S-L, MATHES T, NEUGEBAUER EAM, EIKERMANN M. Systematic review finds overlapping reviews were not mentioned in every other overview. J Clin Epidemiol. 2014;67(4):368-75. https://doi.org/10.1016/ j.jclinepi.2013.11.007.

17. FARAG H, YUNUSA I, GOSWAMI H, SULTAN I, DOUCETTE J, Eguale T. Effectiveness and acceptability of amitriptyline and food and drug administration - approved treatments for fibromyalgia: a network metaanalysis [abstract]. Value Health. 2020;23(supplement 1). https://doi.org/10. 1016/j.jval.2020.04.693

18. THORPE J, SHUM B, MOORE RA, WIFFEN PJ, GILRON I. Combination pharmacotherapy for the treatment of fibromyalgia in adults. Cochrane Pain, Palliative and Supportive Care Group, editor. Cochrane database of systematic reviews. 2018. Available from: https://doi.org/10.1002/14651858. CD010585.pub2. [cited 2019 May 26]

19. SOMMER C, ALTEN R, K-J BÄR, BERNATECK M, BRÜCKLE W, FRIEDEL E, et al. Drug therapy of fibromyalgia syndrome. Updated guidelines 2017 and overview of systematic review articles. Schmerz. 2017;31(3):274-84. https:// doi.org/10.1007/s00482-017-0207-0.

20. SMITH B, Peterson K, Fu R, McDonagh M, Thakurta S. Drug class review: drugs for fibromyalgia: final original report. Portland: Oregon Health \& Science University; 2011. Accessed on: 27 Nov 2018. Available from: http:// www.ncbi.nlm.nih.gov/books/NBK55552/.

21. HÄUSER W, PETZKE F, ÜCEYLER N, SOMMER C. Comparative efficacy and acceptability of amitriptyline, duloxetine and milnacipran in fibromyalgia syndrome: a systematic review with meta- analysis. Rheumatology. 2011; 50(3):532-43. https://doi.org/10.1093/rheumatology/keq354

22. ÜÇEYLER N, HÄUSER W, Sommer C. A systematic review on the effectiveness of treatment with antidepressants in fibromyalgia syndrome. Arthritis Rheum. 2008;59(9):1279-98. https://doi.org/10.1002/art.24000.

23. PERROT S, R-M JAVIER, MARTY M, LE JEUNNE C, LAROCHE F, the CEDR (Cercle d'Etude de la Douleur en Rhumatologie France), French Rheumatological Society, Pain Study Section. Is there any evidence to support the use of anti-depressants in painful rheumatological conditions? Systematic review of pharmacological and clinical studies. Rheumatology. 2008;47(8):1117-23. https://doi.org/10.1093/rheumatology/ken110.

24. MACFARLANE GJ, KRONISCH C, DEAN LE, ATZENI F, HÄUSER W, Fiub E, et al. EULAR revised recommendations for the management of fibromyalgia. Ann Rheum Dis. 2017;76(2):318-28Available from. https://doi.org/10.1136/ annrheumdis-2017-211587.

25. M-A FITZCHARLES, STE-MARIE PA, GOLDENBERG DL, PEREIRA JX, ABBEY S, CHOINIËRE M, et al. 2012 Canadian guidelines for the diagnosis and 
Management of Fibromyalgia Syndrome: executive summary. Pain Res Manag. 2013;18(3):119-26. https://doi.org/10.1155/2013/918216.

26. ROSSY LA, BUCKELEW SP, DORR N, HAGGLUND KJ, THAYER JF, MCINTOSH $\mathrm{MJ}$, et al. A meta-analysis of fibromyalgia treatment interventions. Ann Behav Med. 1999;21(2):180-91. https://doi.org/10.1007/bf02908299.

27. SLUKA KA, Clauw DJ. Neurobiology of fibromyalgia and chronic widespread pain. Neuroscience. 2016;338:114-29. https://doi.org/10.1016/j.neuroscience. 2016.06.006.

28. ROIZENBLATT S, NETO NSR, Tufik S. Sleep disorders and fibromyalgia. Curr Pain Headache Rep. 2011;15(5):347-57Available from. https://doi.org/10. 1007/s11916-011-0213-3.

29. LIMA MLA, MUNUERA A, PEIXOTO D, GUIMARÃES M, SILVA C. The prevalence of depression in fibromyalgia syndrome. Int J Psychiatry. 2016; 21(6). Available from: https://www.polbr.med.br/ano16/art0616.php. [cited 2019 Jul 25].

30. BAKER K, Barkhuizen A. Pharmacologic treatment of fibromyalgia. Curr Pain Headache Rep. 2005;9(5):301-6Available from. https://doi.org/10.1007/ s11916-005-0003-x.

31. DUENAS M, OJEDA B, SALAZAR A, MICO JA, Failde I. A review of chronic pain impact on patients, their social environment and the health care system. JPR. 2016;9:457-67Available from. https://doi.org/10.2147/JPR. S105892.

32. BY THE AMERICAN GERIATRICS SOCIETY 2015 BEERS CRITERIA UPDATE EXPERT PANEL. American Geriatrics Society 2015 updated Beers criteria for potentially inappropriate medication use in older adults. J Am Geriatr Soc. 2015;63(11):2227-46Available from. https://doi.org/10.1001/archinte.164.3. 298.

33. BIDARI A, PARSA BG, GHALEHBAGHI B. Challenges in fibromyalgia diagnosis : from meaning of symptoms to fibromyalgia labeling. Korean J Pain. 2018; 31(3):147-54. https://doi.org/10.3344/kjp.2018.31.3.147.

34. POLLOCK A, CAMPBELL P, HUNT H, ESTCOURT L, Brunton G. Selecting and implementing overview methods: implications from five exemplary overviews. Syst Rev. 2017Available from. https://doi.org/10.1186/s13643-0170534-3.

35. LI G, BHATT M, WANG M, MBUAGBAW L, SAMAAN Z, THABANE L Enhancing primary reports of randomized controlled trials: three most common challenges and suggested solutions. Proc Natl Acad Sci. 2018; 115(11):2595-9. Available from: https://doi.org/10.1073/pnas.1708286114

\section{Publisher's Note}

Springer Nature remains neutral with regard to jurisdictional claims in published maps and institutional affiliations.

Ready to submit your research? Choose BMC and benefit from:

- fast, convenient online submission

- thorough peer review by experienced researchers in your field

- rapid publication on acceptance

- support for research data, including large and complex data types

- gold Open Access which fosters wider collaboration and increased citations

- maximum visibility for your research: over $100 \mathrm{M}$ website views per year

At $\mathrm{BMC}$, research is always in progress.

Learn more biomedcentral.com/submissions 